\title{
Severidade de doenças e manutenção da área foliar verde em função da aplicação de micronutrientes e fungicidas em trigo ${ }^{1}$
}

\author{
Giuvan Lenz ${ }^{2}$, Ivan Francisco Dressler da Costa $^{2}$, Adriano Arrué2, Cezar Coradini² ${ }^{2}$ Valderi Luiz Dressler ${ }^{3}$, Paola de \\ Azevedo Mello ${ }^{3}$
}

${ }^{2}$ Departamento de Defesa Fitossanitária, Universidade Federal de Santa Maria, Centro de Ciências Rurais Prédio 42 - Campus Universitário, CEP 97105900, Santa Maria, RS, Brasil. ${ }^{3}$ Departamento de Química, Universidade Federal de Santa Maria, Centro de Ciências Naturais e Exatas - Campus Universitário. ${ }^{1}$ Parte integrante do Trabalho de Conclusão de Curso do primeiro autor. Universidade Federal de Santa Maria, RS. 2008. Autor para correspondência: Giuvan Lenz (giuvanlenz@gmail.com)

Data de chegada: 06/11/2009. Aceito para publicação em: 10/06/2010.

1656

\section{RESUMO}

Lenz, G.; Costa, I.F.D.; Arrué, A.; Coradini,C.; Dressler, V. L.; Mello, P.A.. Severidade de doenças e manutenção da área foliar verde em função da aplicação de micronutrientes e fungicidas em trigo. Summa Phytopathologica, v.37, n.2, p.119-124, 2011.

Na safra agrícola de 2007 foi instalado um experimento com a cultura do trigo com o objetivo de avaliar a influência do zinco, manganês e molibdênio aplicados juntamente com fungicidas sobre a severidade de doenças e duração da área foliar verde. As aplicações dos fungicidas foram realizadas no final do emborrachamento e no florescimento, e a de micronutrientes, somente no florescimento. Foram analisados os teores de micronutrientes nas folhas, severidade das doenças causadas por Drechslera tritici-repentis e Septoria tritici, índice SPAD (Soil Plant Analysis Development), peso hectolítrico, peso de mil grãos, tamanho de espigas, e rendimento de grãos. O uso do epoxiconazol + piraclostrobina proporcionou o melhor controle de $D$. tritici-repentis e de $S$. tritici. Produtos com epoxiconazol e piraclostrobina atuaram na fisiologia da planta, incrementando os teores de micronutrientes nos tecidos e prolongando o tempo que o trigo permaneceu com área foliar fotossinteticamente ativa. Epoxiconazol + piraclostrobina, piraclostrobina e epoxiconazol pulverizados associados ou não a micronutrientes, propiciaram aumento do peso hectolítrico, peso de mil grãos e rendimento, quando comparados à testemunha.

Palavras-chave adicionais: Drechslera tritici-repentis, Septoria tritici, manganês, zinco, molibdênio

\section{ABSTRACT}

Lenz, G.; Costa, I.F.D.; Arrué, A.; Coradini,C.; Dressler, V. L.; Mello, P.A.. Disease severity and green leaf area maintenance depending on the application of micronutrients and fungicides in wheat. Summa Phytopathologica, v.37, n.2, p.119-124, 2011.

In the crop cycle of 2007, an experiment was carried out in order to evaluate the influence of zinc, manganese and molybdenum sprayed together with fungicides on the severity of diseases and leaf area maintenance in wheat. Fungicides were sprayed at the end of booting and during flowering, whereas micronutrients were only sprayed during flowering. Micronutrients levels in the leaves, severity of diseases caused by Drechslera tritici and Septoria tritici, SPAD (Soil Plant Analysis Development) index, hectoliter weight, thousand-grain weight, ear size, and grain yield were evaluated. The use of epoxiconazol + pyraclostrobin led to a better control of Drechslera tritici and Septoria tritici. Products containing epoxiconazol + pyraclostrobin had an effect on plant physiology by increasing the levels of micronutrients in tissues and prolonging the time during which wheat remained with photosynthetically active leaf area. Epoxiconazol + pyraclostrobin, pyraclostrobin and epoxiconazol sprayed in association or not with micronutrients, led to increased hectoliter weight, thousand-grain weight and grain yield relative to control.

Keywords: Drechslera tritici-repentis, Septoria tritici, manganese, zinc, molybdenum

A cultura do trigo pode ser afetada por doenças bacterianas, viróticas e fúngicas, que dependendo do clima, limitam ou comprometem sua produtividade. As doenças fúngicas que incidem na parte aérea da cultura, como as ferrugens da folha e do colmo, o oídio, e as denominadas de manchas foliares, além das de espiga, como a fusariose, podem causar prejuízos consideráveis. Os prejuízos no rendimento e qualidade dos grãos são maiores quando várias doenças incidem simultaneamente na lavoura.

A planta torna-se mais vulnerável à infecção por patógenos, a partir do estádio de florescimento, em função da maior translocação de nutrientes para o desenvolvimento da espiga e o enchimento dos grãos (3), para algumas doenças necrotróficas como a mancha marrom causada por Bipolaris sorokiniana (Sacc. in Sorok), quanto mais avançada a idade da folha bandeira maior a suscetibilidade da cultura a esse patógeno (19), além disso, no período do florescimento normalmente as condições ambientais são ótimas para o desenvolvimento dos fungos.

O controle químico, em função do seu custo, só é recomendável para culturas com alto potencial produtivo (12), representando um importante papel na garantia da produtividade, desde que empregado com critério, considerando o ciclo biológico do patógeno, o comportamento das cultivares, e as condições ambientais e nutricionais 
(9).

Para ser competitivo no mercado, o triticultor necessita aumentar a produtividade com conseqüente redução de custos. O desenvolvimento de novas cultivares com elevado potencial produtivo implica na exigência de doses mais elevadas de fertilizantes e corretivos e o uso de micronutrientes, pode, segundo Favarin \& Marini (8), ser uma alternativa viável na obtenção desse objetivo.

Trabalhos realizados por Choboussou (5) relatam que o equilíbrio nutricional pode ser considerado um dos principais fatores responsáveis pelo desencadeamento de mecanismos de defesa das plantas. No entanto mais estudos nessa área do conhecimento agronômico objetivando correlacionar os efeitos de nutrientes com a incidência de doenças devem ser pesquisados, pois os elementos minerais estão envolvidos em quase todos os mecanismos de defesa do vegetal, sejam como componentes integrais, ativadores, inibidores e/ou reguladores do metabolismo (20).

Considerando que o controle químico é parte dos componentes que garantem o rendimento da cultura do trigo, especialmente em anos favoráveis a epidemias de doenças foliares e que, muitos agricultores têm utilizado a pulverização de fungicidas como uma via de aplicação de micronutrientes na cultura do trigo, o objetivo deste trabalho foi avaliar o uso de zinco, manganês e molibdênio na manutenção da área foliar verde e seus efeitos na produtividade de grãos.

\section{MATERIAL E MÉTODOS}

O trabalho foi realizado em lavoura comercial de trigo, no município de Itaara - RS, na safra agrícola de 2007, utilizando-se a cultivar FUNDACEP 30. O delineamento experimental foi de blocos casualizados com 22 tratamentos (Tabela 1) e quatro repetições. Os fungicidas e os micronutrientes foram obtidos no comércio local e aplicados conforme a recomendação dos fabricantes. Cada parcela experimental constou de 12 linhas, espaçadas em $0,17 \mathrm{~m}$ e com $5,0 \mathrm{~m}$ de comprimento. Para a área útil, descartou-se as duas linhas externas de cada parcela e $0,5 \mathrm{~m}$ de cada cabeceira.

As aplicações, em número de duas, foram realizadas com o auxílio de um pulverizador costal propelido à $\mathrm{CO}_{2}$, com barra de aplicação dotada de quatro pontas XR 11002 (jato plano de uso ampliado TeeJet $^{\boxplus}$ ) espaçadas em $0,5 \mathrm{~m}$. Após a aplicação de cada tratamento todo o equipamento foi lavado com solução de acetona a $10 \%$, seguida de lavagem com água. A aplicação dos fungicidas foi realizada nos estádios do final do emborrachamento e no florescimento, e a de micronutrientes, somente no de florescimento conforme a escala fenológica de Zadoks et al. (21).

Decorridos 21 dias da segunda aplicação, coletou-se dez plantas por parcela experimental para análise de teores de micronutrientes. As plantas foram secas em estufa com circulação de ar forçada, a $60^{\circ} \mathrm{C}$, até atingirem peso constante. Após, foram trituradas e acondicionadas em sacos de papel.

As determinações de Mn e Zn nas amostras (200 mg de amostra tratada com uma mistura de $2,5 \mathrm{ml}$ de $\mathrm{HNO}_{3}$ e $0,5 \mathrm{ml}$ de $\mathrm{HF}$ concentrados submetido a aquecimento em bloco digestor por $4 \mathrm{~h}$ a $120{ }^{\circ} \mathrm{C}$ ) foram realizadas por espectrometria, utilizando-se um espectrômetro PerkinElmer modelo Optima 4300 DV (Shelton, CT, USA). As linhas de emissão selecionadas para cada elemento foram: Mn 257,610 nm e Zn 206,200 nm. Foram preparadas soluções de calibração entre 5 e $100 \mathrm{mg} \mathrm{l}^{-1}$, em $\mathrm{HNO}_{3} 5 \%$ (v/v), a partir de solução multielementar (SCP33, SCP Science, Canadá). As amostras foram diluídas em $\mathrm{HNO}_{3} 5 \%$ (v/v) pelo fator necessário para ajustar a faixa de concentração da curva de calibração. Para a determinação de Mo utilizou-se espectrômetro (PerkinElmer-SCIEX, modelo Elan DRC II, Thornhill, Canadá). As condições operacionais foram selecionadas de acordo com as recomendações do fabricante e o isótopo selecionado foi ${ }^{98} \mathrm{Mo}$. Foram preparadas soluções de calibração entre 0,1 e $10 \mathrm{mg}$ $1^{-1}$, em $\mathrm{HNO}_{3} 5 \%(\mathrm{v} / \mathrm{v})$, a partir da solução multielementar. As amostras foram adequadamente diluídas, para que ficassem na mesma faixa de concentração da curva de calibração.

As avaliações das doenças foliares ocorrentes Drechslera triticirepentis (Died.) e Septoria tritici (Rob. ex Desm.) foram realizadas após decorridos 21 dias da segunda aplicação dos tratamentos. Para a patometria utilizou-se o percentual de área foliar com sintomas de cada doença (severidade), mensurada em dez folhas-bandeira, coletadas ao acaso, na área útil da parcela experimental de cada repetição. O índice de clorofila ou índice SPAD (teor relativo de clorofila na folha) foi estimado utilizando-se dez folhas-bandeira por parcela em cada repetição, com clorofilômetro marca Minolta (modelo SPAD-502), aos 21 dias após a segunda aplicação. As leituras com o clorofilômetro foram feitas em pontos situados no centro das folhas amostradas.

Determinou-se também o peso hectolítrico $(\mathrm{PH})$, peso de mil grãos (PMG), e o tamanho de espiga (TE), tomando como base 20 espigas. $\mathrm{O}$ rendimento de grãos foi obtido a partir das plantas da área útil da parcela experimental, colhidas e posteriormente trilhadas em trilhadeira estacionária. Os grãos foram pesados, a umidade determinada e corrigida para $13 \%$, para o cálculo do rendimento final. O rendimento relativo (RR) foi calculado através da porcentagem de incremento de grãos em relação à testemunha e a análise dos dados foi realizada pela comparação múltipla de médias de Scott-Knot.

\section{RESULTADOS E DISCUSSÃO}

Os resultados mostraram que as severidades de $D$. triticirepentis e S. tritici foram influenciadas devido à aplicação dos fungicidas e dos micronutrientes, sendo que as menores severidades foram observadas quando foi aplicado $\mathrm{Zn}$ e Mn juntamente com epoxiconazol + piraclostrobina (Tabela 2).

Foi observado que o uso do triazol epoxiconazol associado ou não aos micronutrientes ( $\mathrm{Mn}, \mathrm{Zn}$ e Mo) apresentaram severidades mais elevadas, de $13,2 \%$ (T20) a 26,9\% (T3), do que quando houve mistura com a estrobilurina piraclostrobina, cuja severidade de $D$. tritici-repentis variou de $2,1 \%$ (T5) a 7,2\% (T1), além disso, observouse que o uso da piraclostrobina foi mais eficiente no controle de doenças do que epoxiconazol.

A resistência das plantas a pragas e doenças pode ser induzida pelo efeito da nutrição mineral, causando alterações sobre as estruturas anatômicas, como células epidérmicas e cutículas, parede celular e seu grau de silicificação, suberização e lignificação. Além disso, a nutrição pode afetar as propriedades bioquímicas, como redução de compostos fenólicos que atuam como inibidores do desenvolvimento de pragas e doenças ou acúmulo de compostos orgânicos de baixo peso molecular, como glicose, sacarose e aminoácidos, resultado da maior atividade de enzimas decompositoras como amilase, celulase, protease e sacarase $(18,14)$

Segundo Huber \& Wilhelm (13) há correlação entre o teor de manganês presente no tecido do hospedeiro e a severidade da infecção por doenças, havendo maiores quantidades desse elemento em tecidos saudáveis em relação à plantas doentes ou suscetíveis, que normalmente apresentam menores concentrações. Isto foi observado quando da aplicação de epoxiconazol + piraclostrobina, proporcionando maiores 
Tabela 1. Tratamentos utilizados, doses do produto comercial e ingrediente ativo. Santa Maria - RS, 2007.

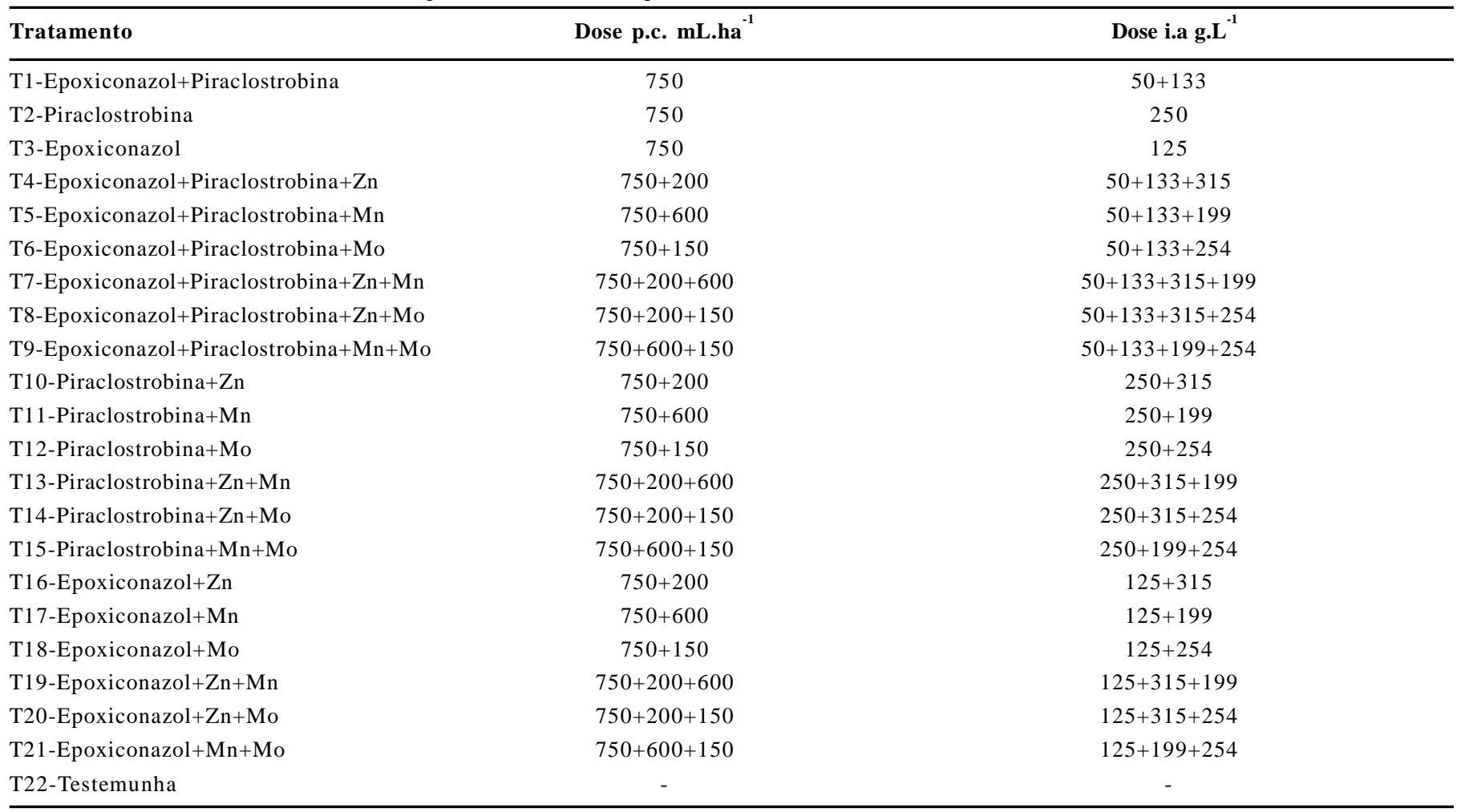

p.c. $=$ Produto comercial

i.a. $=$ Ingrediente ativo

Tabela2. Teor de micronutrientes e severidade de doenças em função dos tratamentos utlizados em trigo (Triticum aestivum). Santa Maria - RS, 2007.

\begin{tabular}{|c|c|c|c|c|c|}
\hline Tratamentos & $\mathbf{T M N}^{1}$ & $\mathbf{T Z N}^{2}$ & TMO $^{3}$ & SD $(\%)^{4}$ & $\operatorname{SS}(\%)^{5}$ \\
\hline T8- Epoxiconazol+Piraclostrobina $+Z n+M o$ & $93,8 b$ & $18,0 \mathrm{~b}$ & $<3,0$ & $3,5 \mathrm{i}$ & $0,1 \mathrm{~h}$ \\
\hline T5- Epoxiconazol+Piraclostrobina+Mn & $82,3 \mathrm{c}$ & $16,4 \mathrm{~g}$ & $<3,0$ & $2,1 \mathrm{j}$ & $0,1 \mathrm{~h}$ \\
\hline T4- Epoxiconazol+Piraclostrobina+Zn & $81,2 \mathrm{c}$ & $17,3 \mathrm{c}$ & $<3,0$ & $4,1 \mathrm{i}$ & $0,1 \mathrm{~h}$ \\
\hline T11- Piraclostrobina+Mn & $75,0 \mathrm{~d}$ & $12,0 \mathrm{r}$ & $<3,0$ & $8,9 \mathrm{~g}$ & $1,2 \mathrm{c}$ \\
\hline T10- Piraclostrobina+Zn & $74,4 d$ & $14,5 \mathrm{n}$ & $<3,0$ & $6,5 \mathrm{~h}$ & $0,4 \mathrm{f}$ \\
\hline T13- Piraclostrobina $+Z n+M n$ & $73,7 \mathrm{e}$ & 14,40 & $<3,0$ & $6,2 \mathrm{~h}$ & $0,5 \mathrm{f}$ \\
\hline T14- Piraclostrobina+Zn+Mo & $73,4 \mathrm{e}$ & $14,0 \mathrm{p}$ & $<3,0$ & $6,8 \mathrm{~h}$ & $0,3 \mathrm{~g}$ \\
\hline T2- Piraclostrobina & $73,0 \mathrm{e}$ & $12,5 \mathrm{q}$ & $<3,0$ & $9,2 \mathrm{~g}$ & $0,6 \mathrm{f}$ \\
\hline T12- Piraclostrobina+Mo & $66,1 \mathrm{~g}$ & $14,4 \mathrm{o}$ & $<3,0$ & $6,9 \mathrm{~h}$ & $0,6 \mathrm{e}$ \\
\hline T21- Epoxiconazol+Mn+Mo & $63,2 \mathrm{~h}$ & 14,71 & $<3,0$ & $26,9 b$ & $0,9 \mathrm{~d}$ \\
\hline T19- Epoxiconazol+Zn+Mn & $60,4 \mathrm{i}$ & $15,4 \mathrm{j}$ & $<3,0$ & $13,2 \mathrm{f}$ & $0,7 \mathrm{e}$ \\
\hline T17- Epoxiconazol+Mn & $59,2 \mathrm{i}$ & $16,6 \mathrm{f}$ & $<3,0$ & $17,4 \mathrm{e}$ & $0,7 \mathrm{e}$ \\
\hline T3- Epoxiconazol & $56,2 \mathrm{j}$ & $14,9 \mathrm{k}$ & $<3,0$ & $24,0 \mathrm{c}$ & $1,7 b$ \\
\hline T20- Epoxiconazol+Zn+Mo & $52,3 \mathrm{k}$ & $16,2 \mathrm{i}$ & $<3,0$ & $13,2 \mathrm{f}$ & $0,9 \mathrm{~d}$ \\
\hline T22- Testemunha & 50,21 & $11,7 \mathrm{~s}$ & $<3,0$ & $73,2 \mathrm{a}$ & $2,6^{\mathrm{a}}$ \\
\hline Coeficiente de Variação (\%) & 5,1 & 6,3 & - & 19,4 & 19,8 \\
\hline
\end{tabular}

${ }^{1}$ Teores de Manganês; ${ }^{2}$ Teores de Zinco; ${ }^{3}$ Teores de Molibdênio; ${ }^{4}$ Severidade causada por Drechslera tritici-repentis; ${ }^{5}$ Severidade causada por Septoria tritici; Médias seguidas da mesma letra na coluna não diferem significativamente pelo teste de Scott-Knot (5\%); ${ }^{\text {n.s. }}$ não significativo. 
TABELA 3. Tamanho de espigas (TE), peso hectolítrico (PH), peso de mil grãos (PMG), produtividade de grãos (PG) e rendimento relativo (RR) em função dos tratamentos utlizados em trigo (Triticum aestivum). Santa Maria - RS, 2007.

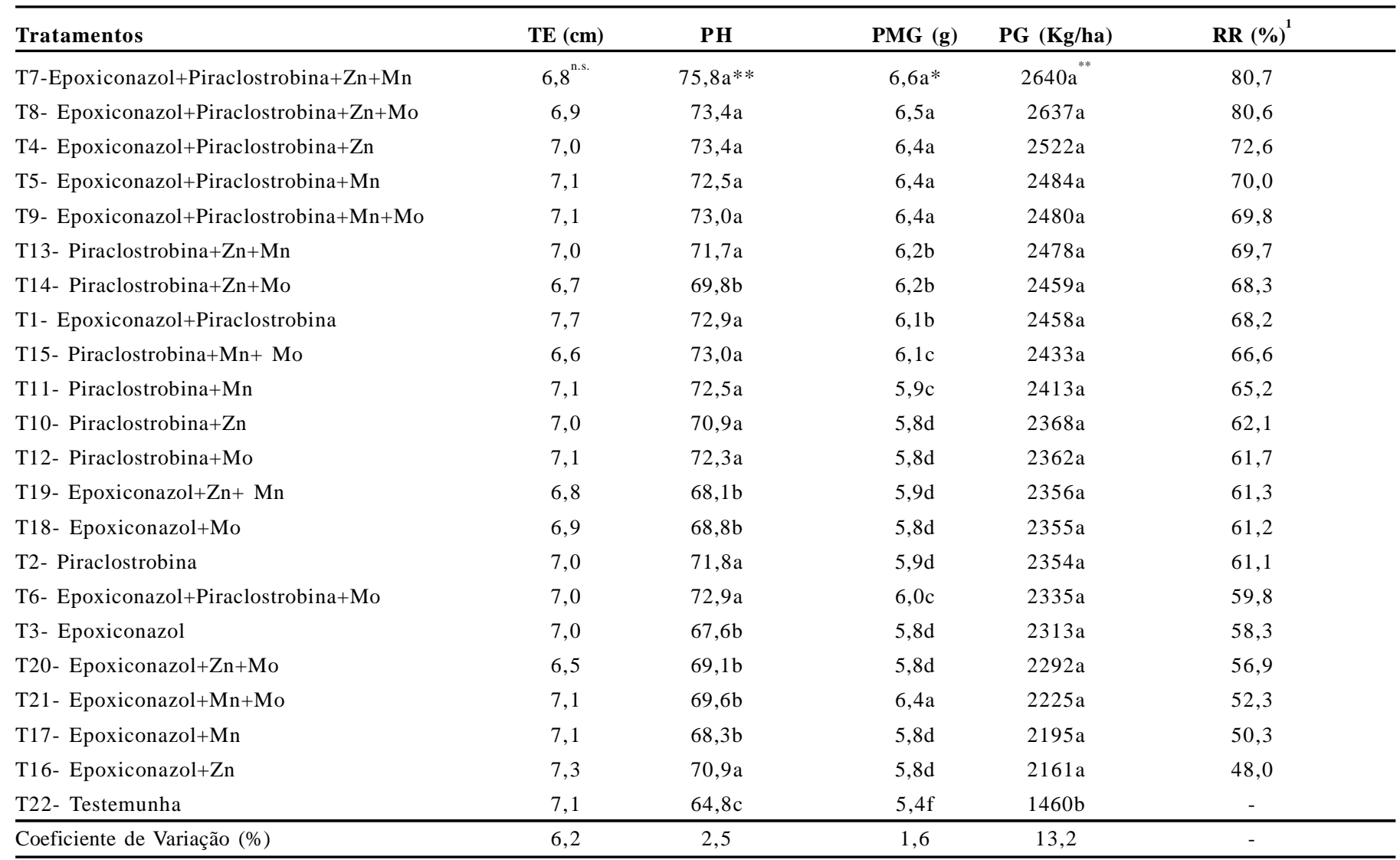

${ }^{1}$ Incremento de rendimento de grãos em relação ao tratamento testemunha; * Médias seguidas da mesma letra na coluna não diferem significativamente pelo teste de Scott-Knot (1\%); ** Médias seguidas da mesma letra na coluna não diferem significativamente pelo teste de Scott-Knot $(5 \%)$; ${ }^{\text {n.s. }}$ não significativo.

teores de micronutrientes no tecido vegetal (Tabela 2 e Figura 2).

Quando se aplicou os princípios ativos piraclostrobina e epoxiconazol em separado, verificou-se que piraclostrobina resultou em maior teor de Mn em relação ao tratamento com epoxiconazol, enquanto que com a aplicação de epoxiconazol maiores teores de $\mathrm{Zn}$ foram observados (Tabela 2). Juntamente com a maior disponibilidade dos micronutrientes, proporcionada pela aplicação dos fungicidas, foi observada também diminuição na severidade das doenças, com pequeno incremento de produtividade.

Alguns trabalhos mostram diferentes respostas de cultivares de trigo ao tratamento químico, sendo as mais suscetíveis aquelas que freqüentemente apresentam maiores ganhos em produtividade, após aplicação de fungicidas $(10,2)$. Outras características inerentes às mesmas, como o ciclo, também podem ser importantes na resposta ao controle químico (7). Barros et al. (4) observaram que a maioria das cultivares apresentam grande resposta em rendimento e peso de mil grãos ao tratamento químico, e essa resposta pode ser maior em anos com condições climáticas mais favoráveis para a cultura e em alguns casos, em cultivares de ciclo mais longo.

A utilização de princípios ativos do grupo das estrobilurinas como a piraclostrobina tem levado diversos pesquisadores a atribuírem seus efeitos ao aumento da fotossíntese líquida e da atividade da enzima nitrato-redutase, combinado com a redução da produção de etileno. $\mathrm{O}$ aumento de atividade da enzima nitrato-redutase resulta também em maior produção de proteínas, fundamentais para a boa nutrição das plantas. A redução da síntese de etileno se traduz na diminuição da senescência das folhas, proporcionando atividade fotossintética prolongada (16) e esse fato pode ser observado nos resultados deste trabalho já que na maioria dos casos as produtividades, e principalmente nas variáveis relacionadas a qualidade, melhores resultados foram alcançados quando o princípio piraclostrobina foi utilizado combinado com epoxiconazol.

Os tratamentos utilizados nesse experimento não influenciaram significativamente a variável tamanho de espigas (Tabela 3), sendo que para variável peso hectolítrico observou-se que os melhores resultados foram obtidos com epoxiconazol + piraclostrobina e piraclostrobina, associados a micronutrientes, seguidos dos tratamentos com epoxiconazol. Os resultados obtidos nessa variável corroboram com os trabalhos desenvolvidos por Gooding, et al. (11) e Dimmock \& Gooding (7) que relatam que os componentes de produção mais influenciados pelo tratamento com fungicidas são o peso e o tamanho dos grãos. Resultados obtidos por Akanda \& Mundt (1) constataram que o peso de grãos foi a variável mais negativamente influenciada pelas doenças. Os aumentos no tamanho e peso dos grãos podem ser atribuídos não só ao controle das doenças, mas também à maior translocação de nutrientes $(11,7)$, sendo que os tratamentos utilizando micronutrientes foram os que apresentaram melhores resultados, devido a maior disponibilidade dos mesmos para formação de compostos necessários ao enchimento dos grãos. Foi observado incremento no ciclo da cultura com a utilização de piraclostrobina e micronutrientes que pode ser atribuido, ao efeito da estrobilurina e dos micronutrientes que proporcionaram maior tempo de atividade 


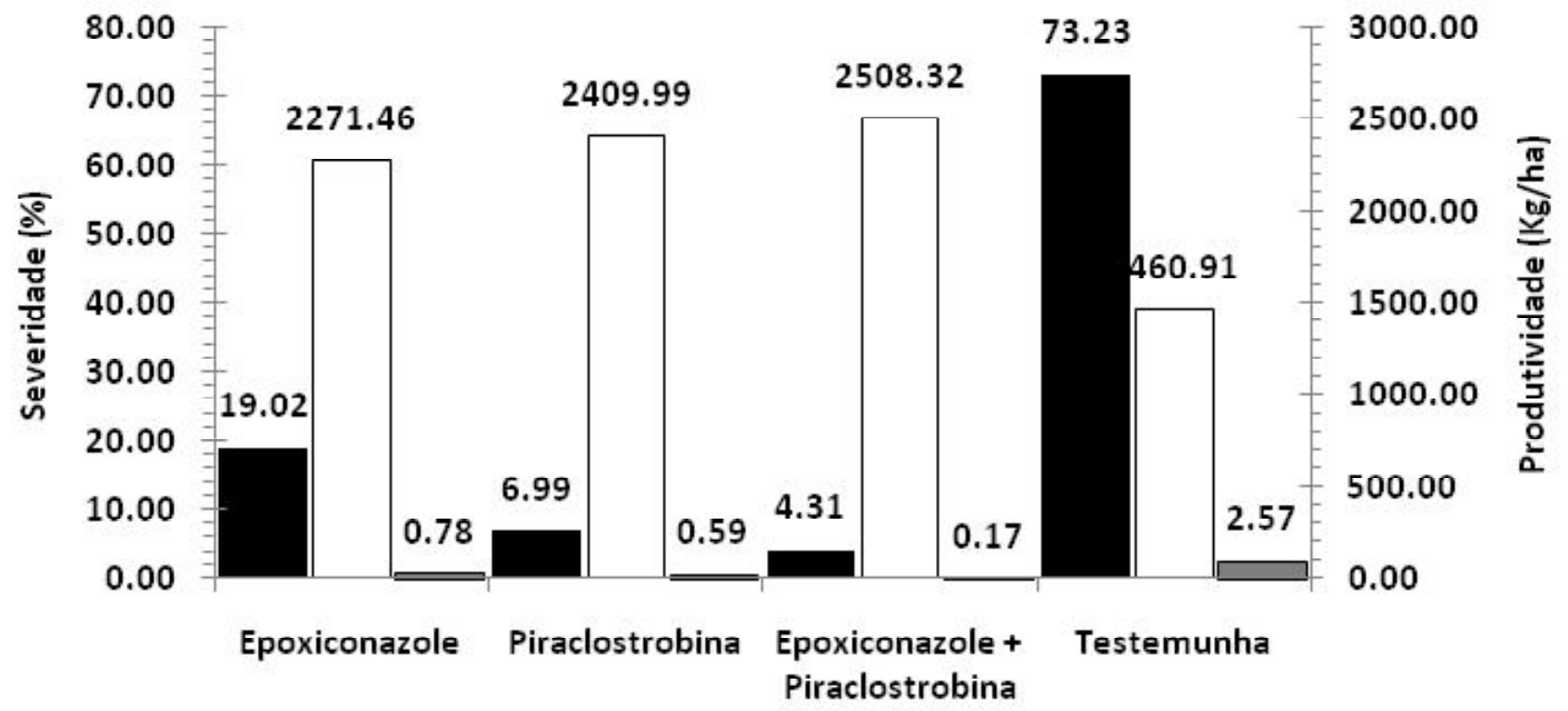

- Sev. Drechslera $\quad \square$ Sev. Septoria $\quad \square$ Produtividade

Figura 1 - Severidade de Drechslera tritici-repentis e Septoria tritici e produtividade em função da média dos tratamentos fungicidas aplicados em trigo (Triticum aestivum). Santa Maria - RS, 2007.

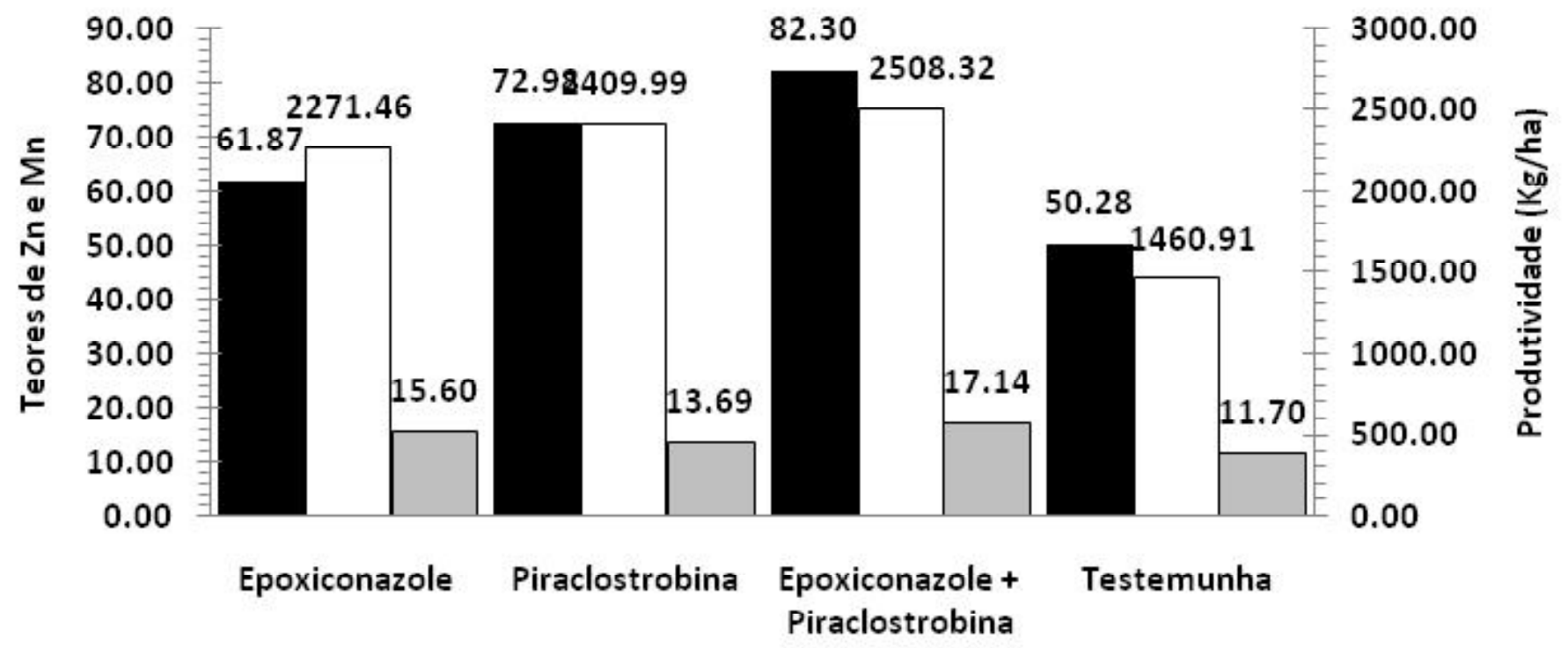

- Teor Mn $\quad \square$ Teor $\mathrm{Zn} \quad \square$ Produtividade

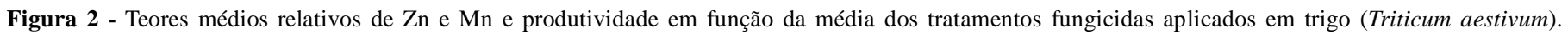
Santa Maria - RS, 2007.

fotossintética às folhas.

A análise do peso de mil grãos ( $\mathrm{PMG})$ foi significativa $(\mathrm{P}=0,01 \%)$, revelando que, quando se utilizou os princípios ativos epoxiconazol + piraclostrobina associados a $\mathrm{Zn}, \mathrm{Mn}$ e Mo, o peso de mil grãos foi maior. Essas observações já haviam sido relatadas por Panisson et al. (17) que em trabalho realizado com o efeito da época, do número de aplicações e de doses de fungicida no controle da giberela em trigo observaram que aplicações na floração plena determinaram incremento no rendimento, peso hectolítrico e no peso de mil de grãos.
Avaliações visuais nas parcelas tratadas com epoxiconazol + piraclostrobina e piraclostrobina associados a $\mathrm{Mn}$ e $\mathrm{Zn}$ foram caracterizadas por uma coloração verde mais intensa quando comparada com os demais tratamentos. Esses sintomas foram observados decorridos sete dias após a primeira aplicação até o final do ciclo da cultura, sendo que, a área foliar das parcelas-testemunha teve sua senescência completa antecipada em cerca de 12 dias em relação aos tratamentos com epoxiconazol + piraclostrobina e piraclostrobina. Estudos realizados por Cook et al. (6) verificaram que a aplicação de 
fungicidas, do grupo das estrobilurinas, podem prolongar o ciclo da cultura, mantendo a área foliar verde, impactando positivamente sobre o rendimento de grãos confirmando os dados obtidos neste trabalho. $\mathrm{O}$ fato de que micronutrientes como o manganês possam interferir e/ ou atuar na síntese de clorofila é relatado por Favarin \& Marini (8) onde, esses autores reportam que a deficiência deste micronutriente e a oxidação excessiva da clorofila são responsáveis pela substituição da cor verde por um tom esbranquiçado, diminuição da fotossíntese e produtividade de grãos.

O manejo das doenças do trigo segundo Mehta et al. (15) preconiza a adoção simultânea de várias práticas como a utilização de cultivares resistentes, o plantio em época adequada, o uso correto de fertilizantes e a aplicação de fungicidas tanto na semente como na parte aérea da cultura. A aplicação de micronutrientes via foliar pode ser uma alternativa na manutenção da área foliar fotossinteticamente ativa e diminuição do nível de doenças, com isso diminuindo as perdas e aumentando a produtividade de grãos.

Com base nos resultados pode-se inferir que epoxiconazol + piraclostrobina proporcionam o melhor controle de $D$. tritici-repentis e $S$. tritici. Os fungicidas epoxiconazol + piraclostrobina, piraclostrobina e epoxiconazol quando aplicados associados ou não a micronutrientes, via foliar, propiciaram aumento do peso hectolítrico, peso de mil grãos e rendimento, quando comparados à testemunha. Produtos com epoxiconazol e piraclostrobina em sua constituição atuaram na fisiologia da planta, incrementando os teores de micronutrientes nos tecidos e prolongando o tempo que a cultura permaneceu com área foliar fotossinteticamente ativa.

\section{AGRADECIMENTOS}

A BASF S.A., pelo reconhecimento do trabalho através do Prêmio TOP CIÊNCIA 2008; ao professor Dr. Osmar Souza dos Santos pelas sugestões no uso dos micronutrientes; ao Fundo de Incentivo à Pesquisa (FIPE) pela bolsa de iniciação científica concedida ao autor e finalmente ao Grupo de Pesquisa em Proteção de Plantas da Clínica Fitossanitária - UFSM pela ajuda na condução do ensaio.

\section{REFERÊNCIAS BIBLIOGRÁFICAS}

1. Akanda, S.I.; Mundt, C.C. Effect of two-components mixture and yellow rust on yield components of wheat. Plant Pathology, v. 46, p. 566-580, 1997.

2. Barros, B.C. Avaliação da resistência varietal e da resposta de cultivares de trigo (Triticum aestivum L.) ao controle químico de oídio, mancha marrom e ferrugem da folha. 1988. p.122. Tese (Doutorado em fitopatologia) - - Escola Superior de Agricultura "Luiz de Queiroz", Universidade de São Paulo, Piracicaba, 1988.

3. Barros, B.C.; Salgado, C.L.; Oliveira, D.A ; Ruiz, E.L.A. Efeito da inoculação artificial de Heminthosporium sativum (PAM.) King
\& Bakke em plantas de trigo em diferentes estádios de desenvolvimento. Arquivos do Instituto Biológico, v. 56, n. 1/2, p. 7577, 1989.

4. Barros, B.C.; Castro, J.L.; Patricio, F.R.A. Response of wheat cultivars (Triticum aestivum L.) to the chemical control of fungal diseases. Summa Phytopathologica, v. 32, p. 239-246, 2006.

5. Chobousou, F. Plantas doentes pelo uso de agrotóxicos: a teoria da trofobiose. 2. ed. Porto Alegre: L \& PM, 1999. 272 p.

6. Cook, R.J.; Hims, M.J.; Vaughan, T.B. Effects of fungicide spray timing on winter disease control. Plant Pathology v. 48, p. 33$50,1999$.

7. Dimmock, J.P.R.E.; Gooding, M.J. The effect of fungicides on rate and duration of grain filling in winter wheat in relation to maintenance of flag leaf green area. Journal of Agricultural Science v. 138 p. 1-16, 2002.

8. Favarin, J.L.; Marini, J.P. Importância dos micronutrientes para a produção de grãos. 2007. Disponível em: http://www.sna.agr.br. Acesso em: 5 fev. 2008.

9. Fernandes, J.M.C.; Picinini, E.C. Sistema de suporte à tomada de decisão para otimização do uso de fungicidas na cultura do trigo. Fitopatologia Brasileira v. 24 p. 9-17, 1999.

10. Giordani, N. A.; Neto, N. Resposta de cultivares e linhagens de trigo a fungicidas - 1985. In: Reunião Nacional de Pesquisa de Trigo, 14, 1986, Londrina. Resumos. Londrina: Iapar, 1986. p.88.

11. Gooding, M.J.; Dimmock, J.P.R.E.; France, J.; Jones, S.A. Green leaf area decline of wheat flag leaves: the influence of fungicides and relationships with mean grain weight and grain yield. Annals Applied Biology v. 136 p. 77-84, 2000.

12. Goulart, A.C.P.; Paiva, F.A.; Melo Filho, G.A.; Richetti, A. Controle de doenças da parte aérea do trigo pela aplicação de fungicidas - viabilidade técnica e econômica. Summa Phytopathologica v. 24 p. 160-167, 1998.

13. Huber, D.M.; Wilhelm, N.S. The role of manganese in resistance to plant disease. Developments in plant and soil sciences v. 33 p. 155-173, 1988.

14. Marschner, H. Mineral nutrition of higher plants. 2. ed. London: Academic Press. 1995. 889 p.

15. Mehta, Y.R.; Riede, C.R.; Campos, L.A.C.; Kholi, M.M. Integrated management of major wheat diseases in Brazil: an example for the Southern Cone region of Latin America. Crop Protection v. 11 p. $517-524,1992$.

16. Oliveira, R.F. Efeito fisiológico do F500 na planta. Atualidades Agrícolas v. 32 p. 9-11, 2005.

17. Panisson, E.; Reis, E.M.; Boller, W. Efeito da época, do número de aplicações e de doses de fungicida no controle da giberela em trigo. Fitopatologia Brasileira v. 27 p. 495-499, 2002.

18. Perrenoud, S. Potassium and Plant Health. 2. ed. Berne. International Potash Institute. 1990. 363 p.

19. Triller, C.; Mehta, Y.R. Efeito da idade da folha bandeira de trigo na expressão de resistência a Bipolaris sorokiniana. Summa Phytopatologica v. 23 p. 167-169, 1997.

20. Zambolim, L. Ventura, J.A. Resistência a doenças induzidas pela nutrição mineral das plantas. Informações Agronômicas Potafos v. 75 p. 1-16, 1996.

21. Zadoks, J.C.; Chang, T.T.; Konzac, C.F. A decimal code for the growth stages of cereals. Weed Research v. 14 p. 415-421, 1974. 